\title{
Perceptions of Adolescent Parenting Among High School Adolescent Students From Selected Rural and Urban Schools in Rwanda
}

\author{
Dieudonne Kayiranga ${ }^{1 *}$, Marie Chantal Uwimana ${ }^{1}$, Alice Nyirazigama ${ }^{1}$, Madeleine Mukeshimana ${ }^{1}$, Patricia Moreland ${ }^{2}$ \\ ${ }^{1}$ School of Nursing and Midwifery, University of Rwanda, College of Medicine and Health Sciences, Kigali, Rwanda \\ ${ }^{2}$ Department of Women's, Children's and Family Health Services, University of Illinois, Chicago, USA
}

Corresponding author: Dieudonne Kayiranga. School of Nursing and Midwifery, College of Medicine and Health Sciences, University of Rwanda, Remera Campus, 11 KG 47, Kigali, Rwanda. Email: kayiranga2@yahoo.co.uk

\begin{abstract}
Background

Adolescent pregnancy is a global public health concern. In Rwanda, adolescent pregnancy has increased from $4.1 \%$ in 2005 to $7.3 \%$ in 2015 and continues to rise.

Objective

To determine adolescents' perceptions of how their lives would change if they experienced an adolescent birth.

Method

A cross-sectional quantitative study. A proportionate stratified random sampling technique was used to select 245 adolescents 15-19 years of age who attended two secondary schools in Rwanda. Data analysis used descriptive and inferential statistics.

Results

The majority of participants had positive perceptions of adolescent parenting. The bivariate analysis showed significant relationships between adolescents' perceptions and three sociodemographic variables (female, pregnancy status, and monthly attendance at the religious group) and one sexual behaviour variable (history of sexual intercourse). The multivariate analysis revealed one significant relationship, females' negative perceptions of adolescent parenting $(\mathrm{p}<0.001)$.
\end{abstract}

\section{Conclusion}

There is a need to strengthen sexual health education programs in secondary schools to raise adolescents' awareness of sexual and reproductive health. Health facilities should provide easy access and affordable contraceptive methods to adolescents, which will help the individual, families, communities and Rwanda.

Rwanda J Med Health Sci 2019;2(2):86-95.

Keywords: Adolescent pregnancy, perceptions, adolescent parenting

\section{Background}

Globally, it is estimated that there are 1.2 billion adolescents, and about 7.3 million girls in developing countries give birth annually.[1] Adolescent girls in sub-Saharan Africa (SSA) have the highest pregnancy rate $(28 \%)$, and the rate is expected to double in the under-15 age group by 2030.[2] This factor is a concern considering pregnancy and childbearing to be the leading cause of death among girls aged between 15-19; [3] therefore, an unplanned pregnancy can have severe consequences for the individual, families, communities, and the country.

To reduce maternal mortality, the World Health Organization (WHO) initiated several programs in order to increase community awareness of the importance of pregnancy prevention, particularly early age occurrence. [4] The WHO strategies have targeted the increased availability and use of contraceptive methods, and the prevention of forced sex involving adolescents. The WHO also aimed to reduce girls early marriage, $(<18$ years) especially in developing countries, in addition to focusing on safe maternal care, access to health care settings, and the reduction of unsafe abortions. [4]

The literature indicated that adults often perceive adolescent parenting as having a negative connotation and consequences; yet, some adolescents perceive pregnancy to be positive encompassing personal growth and leading to adulthood.[5] Conversely, early introduction of sexual behaviours among adolescents 
with multiple sex partners, or unprotected sex, was accompanied by adverse consequences including increased risk of violence,[2] and maternal mortality.[6]

In Rwanda, adolescent pregnancy had increased from 4.1\% in 2005 to $7.3 \%$ in 2015.[7] In 2015, the Ministry of Gender and Family Promotion set up a campaign to prevent unintended pregnancies among adolescents in secondary schools. [8,9] The Ministry of Education also set up a national school health strategic plan (20132018) that included sexual reproductive health education to help manage adolescent pregnancies among schoolaged children.[10]

Although the Demographic Health Surveys (DHS) and local studies have been used to evaluate adolescent perceptions of sex and relationships in Rwanda,[11] little is known about adolescents' perceptions of parenting. A study conducted in 2001 by Condon and colleagues,[12] recommended further research on adolescent pregnancy and parenthood in Rwanda, and to date, it appears no study has been conducted or published. This study aimed to determine adolescents' perceptions of how their lives would change if they experienced an adolescent birth. The findings from this study will enlighten future policies and programs that help control adolescent parenting.

\section{Methods}

\section{Design}

A cross-sectional design was used to gather data at two selected secondary schools in Rwanda, a rural school (Groupe Scolaire Rurenge in the Eastern Province) and an urban school (Groupe Scolaire Gihogwe Catholique in Kigali City). The study was conducted between 10 February and 31 March 2017.

\section{Participants' recruitment}

A total of 671 students listed from all classes made up the sampling frame, of which 245 students aged 15 to 19 years were selected using a systematic random sampling method and interval of three. The sample was equally divided by gender. All students voluntarily accepted to participate in the study.

\section{Measures}

The three-part survey instrument, entitled the 'Thoughts on Teen Parenting Survey' (TTPS) by Herrman and Waterhouse,[13] was designed to assess perceptions of adolescent parenting. The survey consisted of three parts namely; sociodemographic information, the Perceptions of Teen Births Scale, and adolescents' sexual behaviours.

The first part of the survey had nine sociodemographic items including age, gender, economic status, level of religiosity ( $\geq 1$ month), living place, family experience with adolescent parenting (parent and sibling) and family structure. Low economic status was defined as needing financial assistance for food, school fees, school materials or eligibility for free Community-Based Health Insurance (Mutuelle de Santé).

The second part of the survey was an instrument entitled, Perceptions of Teen Births Scale (PTBS) and included 44 items designed to assess adolescents' perceptions. Costs were defined as negative perceptions of the parenting experience, and rewards were defined as positive perceptions. Individuals were asked to rate their level of agreement on a Likert scale from the following responses; strongly disagree, disagree, neutral, agree, strongly agree.

The third part of the survey asked the adolescents about sexual activity and prevention strategies. Questions included past and anticipated behaviours, of sexual intercourse, the age of initiation, number of sexual partners, future sexual intercourse, and the use of condoms.

The self-administered survey was relatively easy to read in the local language, as complicated or confusing words were simplified to control for internal validity. Experts in adolescent reproductive health reviewed the content for consistency and accuracy. An expert in English and Kinyarwanda language translated the survey from English into the local language and back-translated to English.

A pilot study, involved 10 secondary students aged 1519 years from the sampling frame, to test the feasibility of the study, though they were not included in the main study. A careful review of the constructed survey concerning clarity, readability, and appropriateness to the Rwandan context was completed.

\section{Data collection}

Students were invited and approached to participate in the study at school, which was voluntary. The purpose of the study and other pertinent information was explained to students. The study data were kept strictly confidential. The survey was available in Kinyarwanda or English depending upon the participant's preference.

\section{Data analysis}

The tool was used among adolescents to assess their perceptions of adolescent parenting based on "rewards" and "costs." To make the cumulative score, the highest cost (strongly agree) was awarded the lowest score,(1) and the lowest cost (strongly disagree) was awarded the highest score.(5) In addition, the highest reward (strongly agree) was awarded the highest score,(5) and the lowest reward (strongly disagree) was awarded the lowest score (1). When making a composite score, the higher score represents a more positive perception of adolescent parenting (higher rewards, lower costs) and the lower score indicated a more negative perception of adolescent parenting (lower 
rewards, higher costs). The minimum possible score for this scale is 44 , and the maximum is 220 .

Descriptive statistics were used to analyse frequencies, distributions, and means and standard deviations. Bivariate analysis was performed using the chisquare test to measure an association between the demographic, sexual behaviour and adolescents' perception variables, and adolescent parenting. Logistic regression was performed for multivariate analysis to identify the significant factors of adolescent parenting. The demographic variables that were identified were: age, gender, possible financial assistance to the family, being religious or a spiritual person, attendance to any spiritual or religious groups at least once per month, having a parent who was an adolescent parent, living place, the one living with, pregnant status, having children. The sexual behaviour variables included: a history of sexual intercourse, likelihood to have sexual intercourse in the next three months, and a likelihood of condom use with sex in the next three months. The strength of the association of variables was determined by estimating $95 \%$ confidence intervals, and the Odds Ratio.

\section{Ethical considerations}

Permission to conduct this study was obtained from the Institutional Review Board of the University of Rwanda College of Medicine and Health Sciences. In addition, headmasters of both secondary schools had provided written permission to conduct the study in their settings. Participants 18 years or older could sign the consent form, and children under that age had their parents sign the consent form while they themselves signed the assent form. Study participants were reassured of anonymity and confidentiality of the information provided.

\section{Results}

Sociodemographic characteristics of the 245 participants were presented (table 1). The majority were females $(54.3 \%)$, lived with both parents $(51.8 \%)$, and the family did not receive financial assistance $(61.2 \%)$. Almost all (96.3\%) stipulated to be religious or spiritual and attended a group meeting at least once a month $(82 \%)$. Almost all were not pregnant $(92.7 \%)$, or without children (96.3\%). The majority (51.8\%) lived with both parents, nearly a third (31\%) lived with one parent, and others lived with a relative $(7.8 \%)$, an adult $(5.3 \%)$, and some did not specify $(4.1 \%)$. They were fairly evenly represented between urban $(35.9 \%)$, suburban $(40 \%)$, and rural $(24.1 \%)$ areas.
Table 1. Sociodemographic Characteristics

Characteristics n (\%)

\begin{tabular}{|c|c|}
\hline \multicolumn{2}{|l|}{ Age (years) } \\
\hline 15 & $40(16.3)$ \\
\hline 16 & $60(24.5)$ \\
\hline 17 & $54(22.0)$ \\
\hline 18 & $55(22.4)$ \\
\hline 19 & $36(14.7)$ \\
\hline \multicolumn{2}{|l|}{ Gender } \\
\hline Female & $133(54.3$ \\
\hline Male & $112(45.7)$ \\
\hline \multicolumn{2}{|c|}{ Eligible for financial assistance } \\
\hline Yes & $33(13.5)$ \\
\hline Not & $150(61.2)$ \\
\hline Not sure & $62(25.3)$ \\
\hline \multicolumn{2}{|c|}{ Family received financial assistance } \\
\hline No family assistance & $212(86.5$ \\
\hline Food & $5(2.0)$ \\
\hline School fees & $3(1.2)$ \\
\hline School materials & $3(1.2)$ \\
\hline Community health insurance & $14(5.7)$ \\
\hline Food, school fees, materials, & $8(3.3)$ \\
\hline \multicolumn{2}{|c|}{ Considered religious or spiritual } \\
\hline Yes & $236(96.3)$ \\
\hline No & $6(2.4)$ \\
\hline Not sure & $3(1.2)$ \\
\hline \multicolumn{2}{|c|}{ Attend spiritual or religious group } \\
\hline Yes & $201(82.0$ \\
\hline No & $44(18.0)$ \\
\hline \multicolumn{2}{|c|}{ Sibling had an adolescent pregnancy } \\
\hline Yes & $78(31.8)$ \\
\hline No & $147(60.0)$ \\
\hline Not sure & $20(8.2)$ \\
\hline \multicolumn{2}{|c|}{ Parent was an adolescent parent } \\
\hline Yes & $21(8.6)$ \\
\hline No & $184(75.1)$ \\
\hline Not sure & $40(16.3)$ \\
\hline \multicolumn{2}{|l|}{ Pregnancy status } \\
\hline Yes & $4(1.6)$ \\
\hline No & $227(92.7)$ \\
\hline Not sure & $14(5.7)$ \\
\hline \multicolumn{2}{|l|}{ Children } \\
\hline Yes & $9(3.7)$ \\
\hline 1 child & $4(1.6)$ \\
\hline 2 children & $2(0.8)$ \\
\hline$\geq 3$ & $3(1.2)$ \\
\hline No & $236(96.3)$ \\
\hline
\end{tabular}

Adolescents' positive and negative perceptions of adolescent parenting were presented (table 2). The majority agreed their parents would be angry $(76.7 \%)$, they would need more money $(76.3 \%)$ and have less time to spend with friends $(52.7 \%)$. The majority also believed they would have a hard time juggling work and parenting (64.5\%), their life would be more stressful $(68.5 \%)$, and they would get in more trouble $(67.7 \%)$. The majority disagreed with the following two statements: a pregnancy would bring boyfriends and girlfriends closer together (58.4\%), and they would be more likely to graduate from high school $(79.6 \%)$. 
Table 2. Perceptions of Having a Baby and Adolescent Parenting

\begin{tabular}{lcll}
\hline Items & Disagree & Neutral & Agree \\
& $\mathrm{n}(\%)$ & $\mathrm{n}(\%)$ & $\mathrm{n}(\%)$
\end{tabular}

\section{Relationship with peers}

Have more friends

Have less time to spend with friends

Lose friends

\section{Relationship with a boyfriend or girlfriend}

Bring us closer together

Boyfriend would stay in relationship with baby's mother

Makes couples break up

Makes boys feel more like men

Easier to share more child-care responsibilities

An unwelcome surprise

Relationship with family and parents/guardians

Would conflict with my family's values

Parents/guardians would be angry

Family would be closer

Family would help with babysitting

\section{Money status}

Need more money

Money would not be a problem

Family and I would be short of money

Have to learn how to budget more

Have to get a job/another job

\section{Education}

More likely to graduate from high school

Easier to balance school and being a parent

Drop out of school

Do better in school

Career and work

Set higher goals for my future career

Not achieve as much in my future work

Still be able to reach my dreams and goals

Have hard time balancing work and parenting

\section{Personal characteristics}

Be more responsible

Feel better about my life

Conflict with my values

Feel bad about myself

Make better decisions

Feel more grown up

Have bad effect on my (or girl's) body

Take better care of myself

\section{Life in general}

Unable to do sports or school activities

Lose sleep

Upset if my partner were pregnant

Make life easier

Get more attention

Positive effect on my life

Life would be more stressful

\begin{tabular}{|c|c|c|}
\hline $\begin{array}{l}176(71.8) \\
77(31.4) \\
87(35.5)\end{array}$ & $\begin{array}{l}53(21.6) \\
39(15.9) \\
57(23.3)\end{array}$ & $\begin{array}{l}16(6.6) \\
129(52.7) \\
101(41.2)\end{array}$ \\
\hline $\begin{array}{l}143(58.4) \\
125(51.1) \\
102(41.6) \\
82(33.5) \\
138(56.4) \\
89(36.4)\end{array}$ & $\begin{array}{l}37(15.1) \\
38(15.5) \\
54(22.0) \\
51(20.8) \\
49(20.0) \\
67(27.3)\end{array}$ & $\begin{array}{c}65(26.5) \\
82(33.5) \\
89(36.3) \\
112(45.7) \\
58(23.7) \\
89(36.3)\end{array}$ \\
\hline $\begin{array}{l}53(21.6) \\
34(13.9) \\
170(69.4) \\
115(46.9)\end{array}$ & $\begin{array}{l}28(11.4) \\
23(9.4) \\
39(15.9) \\
80(32.7)\end{array}$ & $\begin{array}{l}164(66.9) \\
188(76.6) \\
36(14.7) \\
50(20.4)\end{array}$ \\
\hline $\begin{array}{l}40(16.3) \\
153(62.5) \\
86(35.1) \\
100(40.9) \\
81(33.1)\end{array}$ & $\begin{array}{l}18(7.3) \\
40(16.3) \\
57(23.3) \\
35(14.3) \\
38(15.5)\end{array}$ & $\begin{array}{l}187(76.3) \\
52(21.2) \\
102(41.6) \\
110(44.9) \\
126(51.5)\end{array}$ \\
\hline $\begin{array}{l}195(79.6) \\
52(21.2) \\
78(31.8) \\
189(77.2)\end{array}$ & $\begin{array}{l}25(10.2) \\
56(22.9) \\
47(19.2) \\
26(10.6)\end{array}$ & $\begin{array}{l}25(10.2) \\
137(55.9) \\
120(49.0) \\
30(12.2)\end{array}$ \\
\hline $\begin{array}{l}149(60.8) \\
60(24.5) \\
125(51.0) \\
50(20.5)\end{array}$ & $\begin{array}{l}40(16.3) \\
32(13.1) \\
36(14.7) \\
37(15.1)\end{array}$ & $\begin{array}{l}56(22.8) \\
153(62.5) \\
84(34.2) \\
158(64.5)\end{array}$ \\
\hline $\begin{array}{l}104(42.5) \\
167(68.1) \\
91(37.2) \\
102(41.6) \\
68(27.8) \\
105(42.9) \\
48(19.6) \\
144(58.7)\end{array}$ & $\begin{array}{l}39(15.9) \\
35(14.3 \\
38(15.5) \\
54(22.0) \\
50(20.4) \\
44(18.0) \\
42(17.1) \\
48(19.6)\end{array}$ & $\begin{array}{l}102(41.6) \\
43(17.5) \\
116(36.3) \\
89(36.3) \\
127(51.9) \\
96(39.2) \\
155(63.3) \\
53(21.7)\end{array}$ \\
\hline $\begin{array}{l}98(40.0) \\
104(42.4) \\
64(26.1) \\
184(75.1) \\
113(46.1) \\
186(75.9) \\
53(21.6) \\
56(22.9)\end{array}$ & $\begin{array}{l}31(12.7) \\
41(16.7) \\
37(15.1) \\
24(9.8) \\
48(19.6) \\
27(11.0) \\
24(9.8) \\
24(9.8)\end{array}$ & $\begin{array}{c}116(47.3) \\
100(40.8) \\
144(58.8) \\
37(15.1) \\
84(34.3) \\
32(13.1) \\
168(68.5) \\
165(67.3)\end{array}$ \\
\hline
\end{tabular}

Get labelled in a bad way

$\mathrm{n}(\%)$

n $(\%)$

n (\%) 


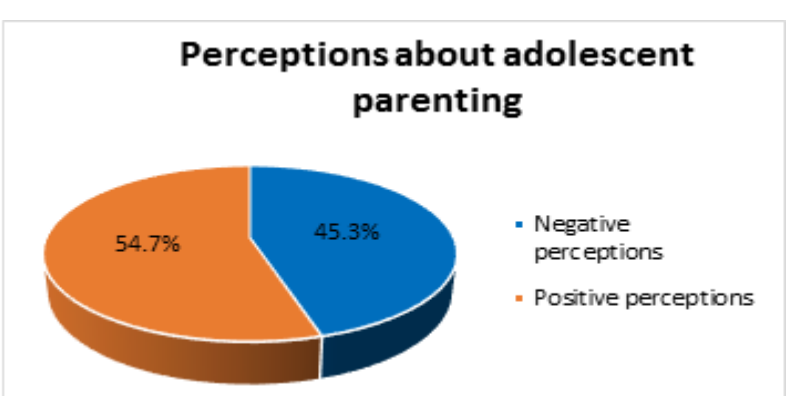

Figure 1. Distribution of negative and positive perceptions of adolescent parenting

Concerning the adolescents' sexual behaviour, over a quarter $(25.3 \%)$ have had sexual intercourse, and most of them ( $80 \%$ ) were 16 years or younger (table 3$)$. Other participants $(14.7 \%)$ were likely to have sexual intercourse in the next three months. Furthermore, many had been with two or more sexual partners in the past $(17.5 \%)$, yet only a few (3.3\%) regularly used condoms.

Table 3. Adolescents' sexual behaviour $(n=245)$

\begin{tabular}{ll}
\hline & $\mathbf{n}(\mathbf{\%})$ \\
\hline History of sexual intercourse & \\
Yes & $62(25.3)$ \\
No & $183(74.7)$ \\
Age of sex initiation (years) & \\
Never had sex & $183(74.7)$ \\
$<15$ & $30(12.2)$ \\
15 & $12(4.9)$ \\
16 & $7(2.9)$ \\
17 & $3(1.2)$ \\
18 & $4(1.6)$ \\
19 & $6(2.4)$ \\
Number of sexual intercourse partners & \\
None & $183(74.7)$ \\
1 & $19(7.8)$ \\
$2-3$ & $16(6.5)$ \\
$\geq 4$ & $27(11.0)$ \\
History of condoms use with sexual intercourse & \\
Never had sex & $183(74.7)$ \\
Always & $8(3.3)$ \\
Often & $10(4.1)$ \\
Sometimes & $4(1.6)$ \\
Seldom & $3(1.2)$ \\
Never & $37(15.1)$ \\
Likelihood of sexual intercourse in next 3 months \\
Very unlikely & $152(62.0)$ \\
Unlikely & $30(12.2)$ \\
Neither likely nor unlikely & $27(11.0)$ \\
Likely & $11(4.5)$ \\
Very likely & $25(10.2)$ \\
Likelihood of condom use with sex in next 3 months & \\
Very unlikely & $111(45.3)$ \\
Unlikely & $41(16.7)$ \\
Neither likely nor unlikely & $39(15.9)$ \\
Likely & $22(9.0)$ \\
Very likely & $32(13.1)$ \\
& \\
\hline & \\
& \\
&
\end{tabular}

The bivariate analysis has shown a significant association between the adolescents' perceptions and the sociodemographic variables: female gender, attendance at a religious or spiritual group at least once a month, and pregnancy status (table 4).

Table 4. Association Between Perceptions of Adolescent Parenting and Demographic Variables

\begin{tabular}{|c|c|c|c|}
\hline \multirow[t]{2}{*}{ Demographic variables } & \multicolumn{2}{|c|}{$\begin{array}{l}\text { Perceptions of } \\
\text { adolescent n (\%) }\end{array}$} & \multirow{2}{*}{ P-value } \\
\hline & $\begin{array}{l}\text { Negative } \\
(n=111)\end{array}$ & $\begin{array}{l}\text { Positive } \\
(\mathrm{n}=134)\end{array}$ & \\
\hline$\overline{\text { Age }}$ & & & 0.399 \\
\hline 15 years & $15(37.5)$ & $25(62.5)$ & \\
\hline 16 years & $26(43.3)$ & $34(56.7)$ & \\
\hline 17 years & $30(55.6)$ & $24(44.4)$ & \\
\hline 18 years & $26(47.3)$ & $29(52.7)$ & \\
\hline 19 years & $14(38.9)$ & $22(61.1)$ & \\
\hline Gender & & & 0.001 \\
\hline Female & $76(57.1)$ & $57(42.9)$ & \\
\hline Male & $35(31.2)$ & $77(68.8)$ & \\
\hline $\begin{array}{l}\text { Possible financial } \\
\text { assistance to the family }\end{array}$ & & & 0.557 \\
\hline Yes & $14(42.4)$ & 19(57.6) & \\
\hline No & $72(48)$ & $78(52)$ & \\
\hline Not sure .. & $25(40.3)$ & $37(59.7)$ & \\
\hline $\begin{array}{l}\text { Being religious or a } \\
\text { spiritual person }\end{array}$ & & & 0.369 \\
\hline Yes & $108(45.8)$ & $128(54.2)$ & \\
\hline No & $3(50)$ & $3(50)$ & \\
\hline $\begin{array}{l}\text { Not sure } \\
\text { Attendance to any }\end{array}$ & $0(0)$ & $3(100)$ & \\
\hline $\begin{array}{l}\text { spiritual or religious } \\
\text { groups at least once per } \\
\text { month }\end{array}$ & & & 0.02 \\
\hline Yes & $98(48.8)$ & $103(51.2)$ & \\
\hline No & $13(29.5)$ & $31(70.5)$ & \\
\hline $\begin{array}{l}\text { Having a parent who was } \\
\text { an adolescent parent }\end{array}$ & & & 0.698 \\
\hline Yes & $8(38.1)$ & 13(61.9) & \\
\hline No & $86(46.7)$ & $98(53.3)$ & \\
\hline Not sure & $17(42.5)$ & $23(57.5)$ & \\
\hline Living place & & & 0.182 \\
\hline Urban & $34(38.6)$ & $54(61.4)$ & \\
\hline Suburban & $51(52)$ & $47(48)$ & \\
\hline Rural & $26(44.1)$ & $33(55.9)$ & \\
\hline The one living with & & & 0.81 \\
\hline Parent & $35(46.1)$ & $41(53.9)$ & \\
\hline Adult/relative & $6(31.6)$ & $13(68.4)$ & \\
\hline Adult/non-relative & $2(50)$ & $2(50)$ & \\
\hline Parents & $60(47.2)$ & $67(52.8)$ & \\
\hline Parent Partner & $3(33.3)$ & $6(66.7)$ & \\
\hline None of the Above & $5(50)$ & $5(50)$ & \\
\hline Pregnant status & & & 0.03 \\
\hline Yes & $0(0)$ & $4(100)$ & \\
\hline No & $108(47.6)$ & $119(52.4)$ & \\
\hline Not sure & $3(21.4)$ & 11(78.6) & \\
\hline Have children & & & 0.517 \\
\hline Yes & $3(33.33)$ & $6(66.67)$ & \\
\hline No & $108(45.76)$ & $128(54.24)$ & \\
\hline
\end{tabular}


The bivariate analysis has shown an association between adolescents' perceptions and sexual behaviour (table 5). There is a statistical significance between history

Table 5. Association Between Perceptions of Adolescent Parenting by Sexual Behaviour of sexual intercourse and adolescents' perceptions $(p=0.017)$.

\begin{tabular}{|c|c|c|c|}
\hline \multirow[t]{2}{*}{ Sexual behaviour } & \multicolumn{2}{|c|}{ Perceptions of adolescent $n(\%)$} & \multirow[b]{2}{*}{$\mathrm{p}$} \\
\hline & $\begin{array}{l}\text { Negative } \\
(n=111)\end{array}$ & $\begin{array}{l}\text { Positive } \\
(n=134)\end{array}$ & \\
\hline History of sexual intercourse & & & 0.017 \\
\hline Yes & $20(32.3)$ & $42(67.7)$ & \\
\hline No & $91(49.7)$ & $92(50.3)$ & \\
\hline Likelihood to have sexual intercourse in the next 3 months & & & 0.065 \\
\hline Very unlikely & $77(50.7)$ & $75(49.3)$ & \\
\hline Unlikely & $15(50)$ & $15(50)$ & \\
\hline Neither likely or unlikely & $8(29.6)$ & $19(70.4)$ & \\
\hline Likely & $2(18.2)$ & $9(81.8)$ & \\
\hline Very likely & $9(36)$ & $16(64)$ & \\
\hline Likelihood to use a condom with sex in the next 3 months & & & 0.266 \\
\hline Very unlikely & $50(45)$ & $61(55)$ & \\
\hline Unlikely & $19(46.3)$ & $22(53.7)$ & \\
\hline Neither likely or unlikely & $23(59)$ & $16(41)$ & \\
\hline Likely & $8(36.4)$ & $14(63.6)$ & \\
\hline Very likely & $11(34.4)$ & $21(65.6)$ & \\
\hline
\end{tabular}

(p-value $\leq 0.05)$

Multivariate analysis showed that among the four independent variables that kept the statistical association with the dependent variable in bivariate analysis, only the variable "gender" positively influenced negative perceptions of adolescent parenting (OR 2.94: 95\%
CI: 1.69-5.11 $\mathrm{p}<0.001$ ) (table 6). Therefore, female adolescents were 2.9 times more likely to have negative perceptions of adolescent parenting than their male counterparts.

Table 6. Association Between Perceptions of Adolescent Parenting and Statistically Significant Demographic Variables and Sexual Behaviour

\begin{tabular}{lll}
\hline Variables & OR $\mathbf{( 9 5 \%} \mathbf{C I})$ & P-value \\
\hline Gender & $2.935(1.687-5.106)$ & 0.001 \\
$\quad \begin{array}{l}\text { Female } \\
\text { Male }\end{array}$ & 1 & \\
$\begin{array}{l}\text { Attendance to any spiritual or religious } \\
\text { groups at least once per month }\end{array}$ & $1.846(0.878-3.879)$ & 0.106 \\
$\quad$ Yes & 1 & \\
$\quad$ No & $4.10^{-9}\left(4.10^{-9}-4.10^{-9}\right)$ & \\
Pregnant status & $3.367(0.865-13.1)$ & 0.08 \\
$\quad$ Yes & 1 & \\
$\quad$ No & & \\
$\quad$ Not sure & $0.796(0.409-1.549)$ & 0.502 \\
Having done sexual intercourse & 1 & \\
$\quad$ Yes & & \\
$\quad$ No &
\end{tabular}

Association: OR (Odds Ratio) $>1$

Protector effect: OR (Odds Ratio) $<1$

Absence of association: OR (Odds Ratio) $=1$

Statistically significant: CI (Confidence Interval) does not contain value 1 and $\mathrm{p} \leq 0.05$ 


\section{Discussion}

This study revealed important findings of adolescents and their perception of how their lives would change if they experienced adolescent birth. The findings revealed that an adolescent birth would have an impact on education, employment, access to finance, relationships with family and friends, future goals, and life in general.

\section{Perceptions of adolescent parenting}

The high cumulative score indicated the majority of adolescents $(54.7 \%)$ had a positive perception of adolescent parenting, which revealed the "rewards" were higher than the "costs" overall. However, when we looked at gender specifically, females were 2.9 times more likely to develop negative perceptions than their male peers, which indicated the cost of adolescent birth exceeded the reward (OR 2.935, CI 1.687-5.106, $\mathrm{p}=0.001)$. This finding is in contrast to Africa's traditional view that the fertility of adolescents promotes childbearing and parenting, and females receive value for motherhood and marital status.[13]

Though the majority of adolescents showed positive perceptions of adolescent parenting, most (96.3\%) did not have children. Similarly, Herrman and Waterhouse,[13] showed that adolescent parenting of non-parenting adolescents in the US was positively associated with gaining money, increased maturity, and opportunity for education when the child was older. In Australia, a perceived additional benefit was an increased individual growth through a transformative experience of adolescent parenting.[5] In contrast, adolescents in South Africa believed their future would be negatively affected as parents separating and blaming each other. [14]

In SSA, adolescents face many challenges that affect their perceptions and their health. Rwandan adolescents face many barriers, such as access to healthcare and literacy, due to medical standards and legal issues that considers them too old for pediatric services, yet too young to make their own decisions with preventive care and treatment.[16] Other barriers in SSA, included lack of sexual-related health education, lack of access to adolescent services, unskilled health workers, lack of privacy, lack of friendly adolescent reproductive health services, expensive contraceptives, and negative perceptions of contraceptives.[17]

Michielsen and colleagues[11] studied young Rwandans' perceptions of sex and relationships and revealed two coexisting stereotypical sexual interactions: Experimental sex by those unprepared and driven by a desire to imitate peer behavior; and transactional sex occurring between younger girls and boys, or older men and women, in exchange for goods or money. The positive perceptions of adolescent pregnancy may be associated with a low level of health literacy that deters adolescents from considering the negative consequences of early risky sexual behaviour. Therefore some adolescents do not learn the balance between the rewards and the costs, which may lead to poor choices. The vulnerability of adolescents with a low health literacy level comes from limited sexual and reproductive health knowledge, lack of guidance or support from adults, and difficulties with accessing condoms.

Participants were students from non-boarding schools who meet with hundreds of peers in their free time without adult supervision. The adolescents had likely received limited information on sexual and reproductive health at school and based on the culture of many Rwandans were too shy to talk about it at home, which may have affected their perceptions. A study in Kenya noted that most discussions that take place at school or in the home do not focus on preventing unplanned pregnancies and are against contraceptive use.[18] Some parents believe that their children should not use contraceptives due to the side effects of the medication. These inhibitory beliefs impact adolescents' access to pregnancy prevention health related information, leading to early child birth.

\section{Association between sociodemographic variables and perceptions}

The majority of participants were female (54.3\%), attended a spiritual or religious group at least once a month $(82 \%)$, and a few $(1.6 \%)$ were pregnant. Bivariate analysis showed that there was a statistical association between gender and perceptions of an adolescent $(p=0.001)$, pregnancy status $(p=0.03)$, history of sexual intercourse $(\mathrm{p}=0.017)$ and attendance at church $(p=0.02)$.

Cross-tabulation highlights the differences in perception based on gender. The majority of males $(68.8 \%)$ had a positive perception, compared to females (42.9\%). Whereas, the majority of females $(57.1 \%)$ had a negative perception of adolescent parenting, compared to males $(31.2 \%)$. This represents the social prospects whereby females experience the majority of parenting responsibilities, while males do not experience the realities of parenting, and its significant impact on their daily lives. [19] In a study conducted in the US, the negative attitudes toward parenting among females related to loss of freedom, decreased ability to enjoy adolescence, and fewer educational and career opportunities. [19]

In contrast, a study published in 2001 by Condon and colleagues in Rwanda,[12] stated that there was no difference between gender when assessing adolescents' attitudes and beliefs about pregnancy and parenthood. The fact that males do not get pregnant and are not blamed for the pregnancy may account for the new finding and current variations of perceptions among 
females and males. Another factor is the promotion of girls' education over the last decade and the desire for them to contribute economically to the family, community and country.

A cross-tabulation of adolescents who do not attend a spiritual or religious group at least once a month had more positive perceptions about adolescent parenting, (70.5\%) compared to those that do attend. Similarly, a study by Osafo and colleagues,[20] highlighted religious values as an umbrella that protected adolescents from misbehaviour, through instruction to engage in riskfree behaviours and less likely involvement in sexual behaviours. In contrast, young adolescents attending social gatherings, such as night prayers, blue movies, and parties experience bad behaviour by observing their peers involved in sexual activities. A study in Uganda [15] found that parents and siblings may be vigilant to protect an adolescent in their family, but once they get the opportunity to imitate their peers, they will likely end up involved in a pregnancy.[15]

The four adolescents with a confirmed pregnancy in the current study indicated positive perceptions of adolescent parenting. These results are supported by a study in Australia, [5] which revealed adolescents who accept and continue with their pregnancy perceive adolescent parenting as a positive and transformative experience that influenced personal growth. Similarly, a qualitative study in South Africa,[14] found that many adolescents perceived benefits from pregnancy, such as proof of one's fertility, increased revenue from older men, enjoyment of sex, believing they would get a grant, and possibly benefit from a second pregnancy. The study also revealed the negative aspects of adolescent pregnancy, such as pregnancy complications, infertility from termination, STI risks including HIV, increased burden of babysitting, and loss of education and employment.[14]

\section{Association between perceptions and sexual behaviour}

The results show that the majority of positive perceptions $(67.7 \%)$ were found among adolescents who had experienced sexual intercourse. The bivariate analysis showed a statistical association between adolescents with a history of sexual intercourse and perceptions of adolescent parenting $(\mathrm{p}=0.017)$. This may relate to feelings of love or being loved, maintaining a relationship, becoming a parent and having a family, or a way to prevent loneliness, as in a US study,[21] but teen males just wanted to have sex; and in contrast, the majority of adolescent females (62.9\%) and males (51.6\%) in Ghana that had sexual intercourse did not show a significant association between preparation for the first sexual intercourse and involvement in pregnancy.[22]

The four variables mentioned above (gender, attendance at church, pregnancy status and history of sexual intercourse) were significant in bivariate analysis, but not with further evaluation through logistic regression. Gender was the only variable that was statistically significant revealing the influence of negative perceptions on adolescent parenting $(\mathrm{p}=0.001)$. Female adolescents were 2.9 times more likely to develop negative perceptions of adolescent parenting than males. This indicated that females were more inclined to have negative perceptions of adolescent parenting than positive perceptions.

Even though the findings revealed that females have more negative perceptions of adolescent parenting than males - which is an increase from the gender-neutral 2001 publication by Condon and colleagues[12] the rate of adolescent pregnancy continues to rise in Rwanda. A report on Family Planning in East Africa showed that Rwanda has a high fertility rate that could hinder the country's goals of becoming a high-income country by 2050.[23,24] The recent gains of lowering the fertility rate, appear to be reversing, in part due to a $7 \%$ increase in adolescent pregnancies. The Ministry of Gender and Family Promotion reported that in 2016 over 17,000 girls aged 16-19 years were pregnant.[23]

Furthermore, this factor resulted in a greater number of girls dropping out of school prior to graduation. Four reasons for the increase in adolescent pregnancy cited gaps in sexual and reproductive health education, hesitancy of religious groups to promote family planning, single adolescents having difficulty accessing family planning and high cost of contraceptives. The report further states that legislators are calling for more intervention to prevent a potential crisis. [24]

The positive perceptions of adolescent parenting among the majority of adolescent students in the study population may account for the increase in early childbearing and school dropouts. Aside from positive perceptions of adolescent parenting, there are potential difficulties accessing healthcare due to the current medical standards that deem adolescents "too old" for pediatric services and yet "too young" to make their own decisions in adult services. A further difficulty has arisen for adolescents in the African context of considering childbearing proof of fertility, as peers and under-informed parents continue to misinform many young Rwandans. Based on these findings, the author noted a need for educational sessions in secondary schools to raise adolescents' awareness of growth changes and sexual reproductive health. Furthermore, adolescents need user-friendly health services that are easily accessible and within their limited budget.

\section{Limitations}

Data were collected from only two schools; therefore, the results cannot be generalised to all schools in Rwanda. Another limitation is that only adolescents attending secondary school were targeted for the study population, so the results cannot be generalised to all adolescents. 


\section{Conclusion}

The results of the study revealed that over half $(54.7 \%)$ of adolescents had positive perceptions of parenting, and nearly half $(45.3 \%)$ had negative perceptions. Females were 2.9 times more likely to have negative perceptions than males. This indicates the attitudes of adolescents toward adolescent parenting, and highlights a need to provide adolescent-centred education on adolescent parenting. An effort to identify the contributing factors for adolescent's perception of adolescent parenting would be beneficial to policymakers to control adolescent parenting. There is a need to increase female education to improve their economic future and decrease the fertility rate and early parenting. This will contribute to the achievement of the Sustainable Development Goals by 2030 , by ending extreme poverty, and the promotion of well-being for all.

\section{Authors contributions}

DK contributed to the original study, data collection, analysis and manuscript writing. MCU and PM supervised the research study, AN performed the quantitative data analyses for the manuscript. MM contributed to the draft of the manuscript.

\section{Acknowledgements}

We acknowledge all participants that made this study successful. We are also grateful to Dr Pamela Meharry for providing helpful orientation to the publication process.

This article is published open access under the Creative Commons Attribution-NonCommercial NoDerivatives (CC BY-NC-ND 4.0). People can copy and redistribute the article only for noncommercial purposes and as long as they give appropriate credit to the authors. They cannot distribute any modified material obtained by remixing, transforming or building upon this article. See https:/ / creativecommons.org/licenses/by-nc-nd/4.0/

\section{References}

1. UNFPA (2017) Adolescent pregnancy. In: News Adolesc. Pregnancy.

2. UNFPA (2013) Adolescent pregnancy: A Review of the Evidence.

3. World Health Organization (2016) Adolescent pregnancy: Maternal, newborn, child and adolescent health. http://www.who.int/maternal_ child_adolescent/topics/maternal/adolescent_ pregnancy/en/ Accessed on January 26, 2017.

4. World Health Organization (2015) Rwanda: Maternal and Perinatal Health Profile.

5. Smith JL, Skinner SR, Fenwick J (2012) Perceptions of teen motherhood in Australian adolescent females: Life-line or life derailment. Women and
Birth 25:181-186

6. Kincaid C, Jones JD, Sterrett E, McKee L (2012) A review of parenting and adolescent sexual behavior: The moderating role of gender. Clin Psychol 32:177-188

7. NISR, MOH, ICF International (2015) Rwanda Demographic and Health Survey 2014-15: Key Indicators. Rockville, Maryland, USA Natl. Inst. Stat. Rwanda [Rwanda], Minist. Heal. [Rwanda], ICF Int.

8. MIGEPROF (2015) Ministry of Gender and Family Promotion of the Republic of Rwanda. Natl Campaign to Fight teenage pregnancy 1

9. NYC (2015) National Youth Center of the Republic of Rwanda. Prev Teen Pregnancy Rwandan Sch 1

10. MINEDUC (2014) National School Health Strategic plan: Ministry of Education of Rwanda. doi: 10.1017/CBO9781107415324.004

11. Michielsen K, Remes P, Rugabo J, Van Rossem R, Temmerman M (2014) Rwandan young people's perceptions on sexuality and relationships: results from a qualitative study using the "mailbox technique." J Soc Asp HIV/AIDS 11:51-60

12. Condon JT, Donovan J, Corkindale CJ (2001) Adolescents' Attitudes and Beliefs About Pregnancy and Parenthood: Results from a School-Based Intervention Program. Int J Adolesc Youth 9:245-256

13. Herrman JW, Waterhouse JK (2011) What Do Adolescents Think About Teen Parenting? West J Nurs Res 33:577-592

14. Kanku T, Mash R (2010) Attitudes, perceptions and understanding amongst teenagers regarding teenage pregnancy, sexuality and contraception in Taung. SA Fam Pr 52:563-572

15. Sekiwunga R, Whyte SR (2009) Poor parenting: teenagers' views on adolescent pregnancies in eastern Uganda. Afr J Reprod Health 13:113-127

16. Binagwaho A, Fuller A, Kerry V, Dougherty S, Agbonyitor M, Wagner C, Nzayizera R, Farmer $\mathrm{P}$ (2012) Adolescents and the right to health: Eliminating age-related barriers to HIV/AIDS services in Rwanda. AIDS Care 24:936-942

17. Yakubu I, Salisu WJ (2018) Determinants of adolescent pregnancy in sub-Saharan Africa: a systematic review. Reprod Health. doi: 10.1186/ s12978-018-0460-4 
18. Kinaro JW (2013) Why adults and teachers information about sexual behavior and its consequences does not prevent unplanned pregnancies among adolescents in Nairobi, Kenya. Health (Irvine Calif) 05:14-23

19. Kegler MC, Bird ST, Kyle-Moon K, Rodine S (2001) Understanding teen pregnancy from the perceptive of young adolescents in Oklahoma City. Health Promot Pract 2:242-254

20. Osafo J, Asampong E, Langmagne S, Ahiedeke C (2014) NIH Public Access. J Reli Heal 1-13

21. Little T, Henderson J, Pedersen P, Stonecipher L (2010) Perceptions of teen pregnancy among high school students in Sweet Home, Oregon. Heal Educ J 69:333-343
22. Morhe ESK, Tagbor HK, Ankobea FK, Danso KA (2012) Reproductive experiences of teenagers in the Ejisu-Juabeng district of Ghana. Int J Gynecol Obstet 118:137-140

23. Rwanda Civil Society Coalition (2018) Midterm assessment report of the implementation of 2015 upr recommendations by the Republic of Rwanda report submitted by Rwanda civil society coaliation to theUnited Nations Human Rights Council.

24. Izugbara CO, Wekesah FM, Tilahun T, Amo-Adjei J, Tsala Dimbuene ZT (2018) Family Planning in East Africa: Trends and Dynamics. African Popul. Heal. Res. Cent. 